\title{
O ARTESANATO EM COURO CRU: GUASQUERIA, IDENTIDADE E TRADIÇÃO NO SÉCULO XXI ${ }^{1}$
}

\author{
Juliana Porto Machado ${ }^{2}$ \\ Ronaldo Bernardino Colvero ${ }^{3}$
}

\begin{abstract}
Resumo: A guasqueria, é um ofício artesanal que trabalha com couro cru, possui técnica de transmissão de um saber fazer, em um processo de criar objetos que segue uma estrutura dorsal, sendo ela: I) Carnear, II) Estaquear, III) Secar; IV) Lonquear; V) Sovar; VI) Tirar tentos e VII) Trançar. Esse ofício está fortemente relacionado com o trabalho do campeiro/peão, figura que está sempre realizando tarefas de campo nas estâncias junto ao cavalo. Assim, o objetivo deste artigo é discutir acerca da tradição como uma ferramenta cultural que está em um processo contínuo de transformação e que influência na identidade dos sujeitos que praticam um ofício secular como a guasqueria. Como metodologia utilizouse pesquisa de natureza qualitativa, do tipo exploratória, com método de entrevistas semiestruturadas para a coleta de informações com três guasqueiros da cidade. Destaca-se como resultado que a produção de guasqueria ocorre pela transmissão da técnica de um sujeito para o outro, principalmente quando estes exercem a profissão de peão. Fazendo com que esses sujeitos praticantes se identifiquem como guasqueiros.
\end{abstract}

Palavras-chave: Guasqueria. Artesanato. Tradição. Identidade.

\section{THE CRAFT IN RAWHIDE: GUASQUERIA, IDENTITY AND TRADITION IN THE 21 ST CENTURY}

\begin{abstract}
The guasqueria, is a craft that works with rawhide, has technique of transmission of a know-how, in a process of creating objects that follows a linear structure, being: I) Carnear, II) Estaquear, III) Secar; IV) Lonquear; V) Sovar; VI) Tirar tentos e VII) Trançar. This craft is strongly related to the work of the campeiro/peão, figure who is always performing field tasks in the ranches togheter the horse. However, in view of this structuring that maintains the objective of this article is to discussing the concept of tradition as a cultural tool that is in a continuous process of transformation and that influence on the identity of the subjects who practice a secular craft like guasqueria. As a methodology was used qualitative research, type exploration, with a semi-structured reading method for an information collection with three city lobsters. It is emphasized as a result that a production of guasqueria can be performed by the transmission of the technique from one subject to the other, especially when exercising a profession of pawn. Making the ways of practicing identify themselves as guasqueiros.
\end{abstract}

\footnotetext{
${ }^{1}$ Este artigo apresenta parte dos resultados obtidos na pesquisa de mestrado intitulada "Artesanato em couro cru (Guasqueria) na cidade de Jaguarão-RS" , realizada no Programa de Pós-Graduação em Memória Social e Patrimônio Cultural (PPGMP) da Universidade Federal de Pelotas (UFPEL) e finalizada no ano de 2018.

2 Mestre e Doutoranda em Memória Social e Patrimônio Cultural pela Universidade Federal de Pelotas (UFPEL), bolsita FAPERGS, Pós-graduanda em Ensino de História pela Univesidade Federal do Pampa (UNIPAMPA-Jaguarão), Bacharela em Produção e Política Cultural (UNIPAMPA-Jaguarão). Email: julianamachado209@gmail.com

${ }^{3}$ Diretor do campus de São Borja - UNIPAMPA, Mestre em História Regional - UPF - Passo Fundo - RS

Doutor em História das Sociedades Ibéricas e Americanas - PUC - Porto Alegre - RS, Prof. Associado da Universidade Federal do Pampa - UNIPAMPA - Campus de São Borja - RS, Professor do Mestrado em Políticas Publicas da UNIPAMPA campus São Borja e do Programa de Pós-Graduação em Memória Social e Patrimônio Cultural - UFPEL. Email: rbcolvero@gmail.com
} 
Keywords: Guasqueria. Crafts. Tradition. Identity.

\section{EL ARTESANATO EN CUERO CRU: GUASQUERIA, IDENTIDAD Y TRADICIÓN EN EL SIGLO XXI}

Resumen: La guasquería, es una artesanía que trabaja con cuero crudo, tiene la técnica de transmisión de un know-how, en un proceso de creación de objetos que sigue una estructura dorsal, siendo: I) Carne de vaca, II) Estaca, III) Seca; IV) Siembra; V) Sovar; VI) Para tomar los intentos y VII) Para trenzar. Esta artesanía está fuertemente relacionada con el trabajo del campeón / peón, figura que siempre está realizando tareas de campo en los ranchos, principalmente con la ayuda del caballo. Sin embargo, en vista de esta estructuración que mantiene el objetivo de este artículo es discutir la valla tradicional como una herramienta cultural que se encuentra en un proceso continuo de transformación y que influye en la identidad de los sujetos que practican una artesanía secular como la guasquería. Como metodología se utilizó investigación de naturaleza cualitativa, del tipo exploratoria, con método de entrevistas semiestructuradas para la recolección de informaciones con tres guasqueros de la ciudad. Se destaca como resultado que la producción de guasquería ocurre por la transmisión de la técnica de un sujeto al otro, principalmente cuando éstos ejercen la profesión de peón. Haciendo que estos sujetos practicantes se identifiquen como guasqueros.

Palabras clave: Guasqueria. Artesanía. Tradición. Identidad.

\section{Introdução}

$\mathrm{O}$ artesanato em couro cru denominado como guasqueria terminologicamente é derivado da palavra espanhola huasca pertencente ao dialeto quéchua de origem inca e significa tira de couro (DLE, 2017). Essa forma de expressão cultural está estreitamente entrelaçada ao trabalho no campo e principalmente com a figura do peão. A inserção do gado vacum no Brasil e em outros países da América latina através dos conquistadores europeus, principalmente os espanhóis e portugueses no início do século XV, de acordo com Alvares (2014) marcam o que seria o surgimento da guasqueria

Nesse artesanato seus produtores, os guasqueiros, criam peças em couro cru, utilizando principalmente a técnica de tentos ${ }^{4}$. De acordo com Flores (1960) o guasqueiro deve aprender a tirar um tento para seguir no ofício para ele essa fase é muito importante, pois é a partir do tento que se inicia o processo de elaboração da obra. A guasqueria possui uma estrutura dorsal que se apresenta como: a obtenção da matéria-prima (o couro-cru animal principalmente de bovinos) inicialmente através da chamada carneada, o estaquear o couro para secar ao sol, o lonquear de retirar os pêlos da pele, o cortar as guascas (tiras de

\footnotetext{
${ }^{4}$ A técnica de tentos de acordo com Flores (1960) pode ser definida como a utilização de tiras finas de couro utilizadas para fazer trançados.
} 
couro), o sovar as guascas para amaciar e por fim tirar os tentos (as tiras de couro de diferentes espessuras) para assim produzir as tranças. Esse processo é o elemento destacado por muitos sujeitos ao considerarem o porquê de se identificarem como guasqueiros, assunto que será aprofundado neste artigo.

Historicamente a guasqueria surge com a introdução no gado bovino e equino em regiões localizadas ao sul do Brasil em que a vegetação era propícia para esses animais sobreviverem. Com foco no Rio Grande do Sul, no início do século XVI os jesuítas fixavam suas reduções nesse território e reúnem indígenas para serem catequizados e começam a utilizar a carne gado bovino para alimentação dos moradores das reduções. No entanto, ao serem expulsos os jesuítas deixam seus grandes rebanhos soltos.

Em 1641, depois de combatidos e expulsos, os jesuítas levaram consigo a maioria dos índios catequizados, deixando, no entanto, parte do gado que criavam. Sem dono, esse gado tornou-se selvagem e bravio, e formou-se uma grande reserva no espaço conhecido como Vacarias Del Mar (LUVIZOTO, 2010; p. 17).

Consequentemente, com a abundância desses animais esse gado acaba tornando-se importante economicamente, aproveitando-se a carne e principalmente o couro. Com o retorno dos jesuítas em 1682 e a fundação das missões jesuítas que buscavam catequizar o maior número de índios, os padres utilizavam novamente esse gado para alimentação. Pois, "a base econômica era assentada na criação de gado com a extração do couro" (Luvizoto, 2010; p 22).

No século XVIII, as fazendas ganham espaço e o gado passa a ser domesticado. Surgindo assim, a necessidade de instrumentos equestres para auxiliar no manejo desses animais, principalmente para o peão que cuidava da atividade campeira. Por conseguinte, de acordo com Garcia (2009), com o abate dos animais para a comercialização de carne, o couro começa a ser utilizado para atender essa necessidade de objetos equestres quando os peões começam a criar cordas, freios, boleadeiras, rebenques e outros aparatos em couro-cru.

Para Flores (1960), o peão dedicava-se ao processo de produção de guascas principalmente em dias de chuvas quando não era possível trabalhar no campo, assim permanecia no galpão consertando suas cordas.

Desse modo surge o guasqueiro.

Na campanha sempre existiram os guasqueiros, os homens que do couro cru fazem verdadeiras obras-primas nas tranças, nos passadores, nos botões de tento fino e em muitos trabalhos que exigem muita paciência, muito boa memória para saber 
resolver de cor os intrincados da trama dos tentos, que é um verdadeiro quebracabeça. (NUNES 1982 apud ALVARES, 2014, p. 17).

Então o guasqueiro seria esse sujeito que cria manualmente novos objetos e/ou conserta objetos de uso cotidiano do trabalho do campo. Dominando o saber fazer de um ofício, para desenvolver suas próprias técnicas. A guasqueria está ligada ao serviço do peão, as peças então são instrumentos de montaria em uma sociedade em que a produção econômica forte é a pecuária (NUNES, 1982).

A partir de então no século XIX o guasqueiro torna-se um profissional necessário nas grandes fazendas, agora reconhecido e contratado especificamente para realizar essa prática artesanal. Já no final desse período o guasqueiro passa a ser menos requisitado, pois com as reviravoltas da sociedade econômica no período da Revolução Industrial, no RS a pecuária e a agricultura não são mais as únicas formas de produção já que as atividades fabris surgem (ALVARES, 2014).

Para compreender esses processos de transformação da guasqueria utilizou-se pesquisa de natureza qualitativa, do tipo exploratória, com método de entrevistas semiestruturadas para a coleta de informações com quatro guasqueiros da cidade. Visto que, é através da pesquisa que se encontram formas de solucionar o problema levantado. A pesquisa pode ser compreendida de acordo com Gil (1996), como um processo de desenvolvimento do método científico. Para Seltiz (1974) o pesquisador tem a necessidade de organizar e planejar sua pesquisa, e também de escolher o método mais adequado para atingir as metas estabelecidas.

Assim, através da pesquisa qualitativa de acordo com Zanelli (2002), se permite que a cultura dos sujeitos investigados consiga transmitir sua essência. Uma vez que, essa abordagem possibilita a esses uma estruturação de suas perspectivas e de seus saberes adquiridos ao longo do tempo. Transmitindo sua visão intrínseca de mundo. Isto posto, torna a análise do objeto de estudo em plurefacetado, já que, o objeto está em um processo constante de transformação.

Dessarte, em uma pesquisa que envolve sujeitos sociais, se torna primordial compreender a construção dos fatos realizados por esses. Nesse sentido, a pesquisa qualitativa "adequa-se a aprofundar a complexidade dos fenômenos, fatos e processos particulares e específicos de grupos mais ou menos delimitados em extensão e capazes de serem abrangidos intensamente" (MINAYO E SANCHES, p. 247; 1993).

Todavia, buscamos neste artigo discutir sobre a tradição como um elemento cultural 
que está sempre em transformação e que influência na identidade dos sujeitos que praticam um ofício tradicional como a guasquería. Trabalhando com o depoimento de quatro guasqueiros da cidade de Jaguarão (Figura 01), localizado no extremo sul do Rio Grande do Sul (RS).

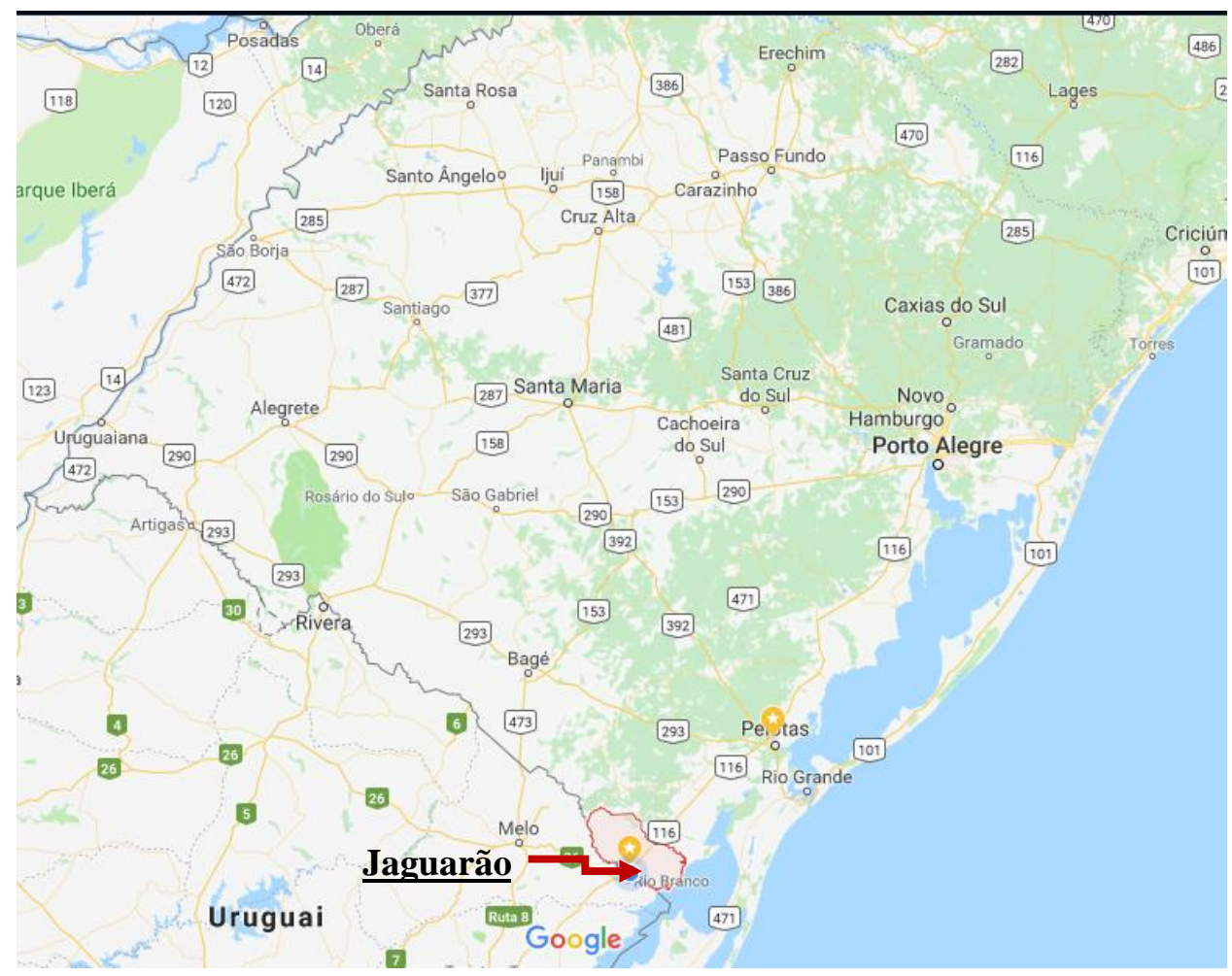

Figura 1-Localização de Jaguarão no mapa do Estado do Rio Grande do Sul

Fonte: GOOGLE MAPS (2018)

O artigo está organizado em Introdução, em que se aborda o objetivo da discussão, apresentando a metodologia utilizada assim como uma breve contextualização da guasqueria e das fontes utilizadas. Logo, será dividido em dois componentes. Sendo o primeiro denominado "A tradição que se transforma", no qual se trabalha o conceito de artesanato e tradição, como também compartilhamento de um saber fazer e de elementos atuantes na estruturação do objeto guasqueria e guasqueiros. O segundo componente será "Guasqueiro ou artesão: A identidade e os guascas", em que trataremos de questões referentes a identidade desses sujeitos praticantes de um ofício tradicional. E por fim, apresentaremos as considerações finais, estabelecendo uma relação de pontos em comum entre as informações encontradas junto aos guasqueiros. 


\title{
A Tradição que se transforma
}

O artesanato classificado como tradicional pode ser definido de acordo com o $\operatorname{SEBRAE}^{5}$ (2010, p.14) como o "conjunto de artefatos mais expressivos da cultura de um determinado grupo, representativo de suas tradições, porém incorporados à sua vida cotidiana”. Essa forma de produção baseia-se na estrutura familiar, na representação cultural de uma comunidade. No conhecimento gerado e difundido de uma geração a outra. Com isso, se faz importante explorarmos a construção de uma tradição, e sendo assim, partiremos da ideia de costume, momento em que, no século XVIII, na Europa os costumes ainda permaneciam e estavam presentes nesse contexto de forma arreigada.

Thompson (1998) salienta que "costume" seria a ação comum que praticam um grande número de indivíduos, ou, em suas palavras "a segunda natureza do homem" (p.14). Seguidamente, com a emergência de um novo tempo (Era Industrial) que supostamente transformaria a cultura do povo, não haveria a necessidade da permanência de certos costumes antigos/primitivos/bárbaros, já que não possuiriam mais representatividade. Pois, a cultura definida nos termos de Thompson parte da declaração:

\begin{abstract}
Não podemos esquecer que "cultura" é um termo emaranhado, que, ao reunir tantas atividades e atributos em um só feixe, pode na verdade confundir ou ocultar distinções que precisam ser feitas. Será necessário desfazer o feixe e examinar com mais cuidado os seus componentes: ritos, modos simbólicos, os atributos culturais da hegemonia, a transmissão do costume de geração para geração e o desenvolvimento do costume sob formas historicamente específicas das relações sociais e de trabalho (1998; p.22).
\end{abstract}

$\mathrm{O}$ autor demonstra em suas palavras a importância de percebermos a cultura em seus detalhes pormenores, em seus componentes de estruturação, dos costumes, tradições e identidade para se iniciar um processo de compreensão da diversidade cultural. Assim como Thompson, Geertz (2008) irá afirmar que a cultura não é algo fácil de ser interpretada como uma história já escrita, ao contrário, se faz complexa devido aos fatos sociais e às mudanças de contexto.

Para Thompson a educação e religião (da classe alta), teoricamente direcionariam a vida de todos e eliminariam certos costumes das classes inferiores.

Para que a sociedade seja feliz e o povo tranquilo nas circunstâncias mais adversas, é necessário que a grande parte dele seja ignorante e pobre. O conhecimento não só

\footnotetext{
5 SEBRAE é o Serviço Brasileiro de Apoio às Micro e Pequenas Empresas. Cuja função é estimular o empreendedorismo no Brasil (SEBRAE, 2010).
} 
amplia como multiplica nossos desejos [...] portanto, o bem-estar e a felicidade de todo Estado ou Reino requerem que o conhecimento dos trabalhadores pobres fique confinado dentro dos limites de suas ocupações e jamais se estenda (em relação as coisas visíveis) além daquilo que se relaciona com sua missão. Quanto mais um pastor, um arador ou qualquer outro camponês souber sobre o mundo e sobre o que é alheio ao seu trabalho e emprego, menos capaz será de suportar as fadigas e as dificuldades de sua alegria e contentamento. A leitura, escrita e a aritmética (...) são muito perniciosas aos pobres (MANDEVILLE apud THOMPSON, 1998; p.15).

A busca para terminar com costumes ancestrais, de acordo com o autor, ocasionou uma alienação que acometeu a Europa e a partir disso surgiu a ideia de folclore ${ }^{6}$, onde pesquisadores da camada superior buscavam compreender e registrar os excêntricos ritos e tradições da plebe, como se tratando de fenômenos exóticos. Como consequência, o folclore nasce do preconceito da ilusão de superioridade de uma classe social em relação a outra. O costume então torna-se objeto do passado que ainda sobreviveria timidamente no presente com poucos vestígios, às margens da modernização (THOMPSON, 1998).

No século XIX, colecionadores começaram a procurar resquícios dos costumes da classe tida como inferior que era fonte de interesse, pela peculiaridade, já que possuíam modos incompreensíveis de vida aos olhos da elite. De tal modo, esses costumes tornaramse obsoletos, rudimentares, porque foram reinterpretados fora de seu contexto de atuação, de acordo com o autor precitado. Então suas práticas ao olhar externo sem referência, acabam por tornarem-se meramente superficiais, desprovidas de carga simbólica.

Nessa perspectiva, muitas das reinvindicações feitas pela emergente cultura dos trabalhadores na primeira Revolução Industrial, como melhoria nas condições de trabalho e na adequação de um salário justo, buscam também retomar seus antigos costumes. Por exemplo, as procissões em agradecimento a uma divindade ligada ao ofício que no século XVIII eram celebradas, mas foram interrompidas no século XIX. Porém, Thompson advoga que costume não pertence à tradição ${ }^{7}$, é um elemento de discussão, de transição e de mudança.

No contexto industrial, ideias e direitos que antes eram salvaguardados e garantidos pelos direitos consuetudinários fundamentados em tempos imemoriais, partindo de costumes como base de lei, acabam por perder importância e espaço, a memória dos mais

\footnotetext{
${ }^{6}$ Folclore I - Narrativas tradicionais (contos populares, contos de heróis, baladas e canções, lendas); II Costumes tradicionais (costumes locais, festas consuetudinárias, cerimônias consuetudinárias, jogos); IIISuperstições e crenças (bruxaria, astrologia, superstições e práticas de feitiçaria); IV - Linguagem popular (ditos populares, nomenclatura popular, provérbios, refrães e adivinhas) (ALMEIDA, 1974, p.11).

${ }^{7}$ Neste contexto Thompson (1998) considera tradição como algo fixo e imutável.
} 
velhos já não possui o mesmo poder. Esta inclinação do autor demonstra a força que os anciões possuem em limitar as regras de condutas. Eles acabam perdendo espaço quando os gestos, as atitudes, os hábitos e as tradições passam por um processo de readaptação na modernidade, principalmente no sistema trabalhista.

Em outro prisma, tradição e costumes se diferem, de acordo com Gadamer (1996) eles não podem ser igualados. Os costumes possuem a impossibilidade de se concretizarem de forma espontânea e livre, para tanto, sua efetivação ocorre fundamentalmente pela tradição, sendo esta compreendida através do ponto de vista de que os hábitos e linguagens adquiridos de uma cultura através das trocas dos indivíduos lhe pertencem em um foro social.

Consequentemente, este fato nos insere em um mundo histórico que nos antecede, em que somos limitados ao acessá-lo. Alguns elementos se conservam e se transformam a partir de um novo olhar e necessidade. Desse modo:

\begin{abstract}
Em nosso comportamento com respeito ao passado, que estamos confirmando constantemente, a atitude real não é a distância nem a liberdade com respeito ao transmitido. Pelo contrário, nos encontramos sempre em tradições, e este nosso estar dentro delas não é um comportamento objetivador que pensou como estranho ou alheio o que disse a tradição; esta é sempre mais algo próprio, exemplar ou aborrecível, é um reconhecer-se naquilo que para nosso juízo histórico posterior não se percebe apenas conhecimento, senão um imperceptível ir transformando-se ao passo da mesma tradição (GADAMER, 1996, p. 350).
\end{abstract}

Segundo o autor, alguns elementos de reprodução estão presentes na tradição, porém, ela não significa apenas isso. $\mathrm{O}$ encontro entre passado e presente, a constitui. Nesse sentido, se produz algo no presente que pertence ao passado, mas com um novo significado. Então em cada contexto, por exemplo, uma técnica será interpretada de forma diferente. O caráter de permanência da tradição se confirma quando cada cultura conserva alguma característica que simboliza o que era anteriormente, só que no presente sofre com o hibridismo ${ }^{8}$.

Para Gadamer (1996), não existem meios de adquirir uma apropriação plena da tradição. Ela pertence a outra dimensão do conhecimento, seu arcabouço está calcado na conservação, mas também na mobilidade do tempo e da cultura, sempre em transformação. Nessa concepção, a tradição permite a liberdade de expressarmos o passado sem repeti-lo

\footnotetext{
8 Hibridismo essa transformação de uma cultura, em troca constante com uma ou mais culturas. Em que os valores são repensados, e transformados. Uma cultura múltipla, diversa que está sempre em um processo de combinação de conhecimentos (GADAMER, 1996).
} 
integramente, e sim modificando-o em um diálogo constante com o presente. Essa fronteira limitada se apresenta na situação de que a razão humana não consegue abarcar tudo. Os atores culturais são seres ativamente produtores, criam e recriam uma cadeia de valores hierárquicos. Alguns expoentes são mais legitimadores que outros, no caso a tradição que carrega em si um legado de veracidade e elementos memorizantes de forte ação.

Dessa forma, as tradições nascem, como afirma Barth (2000), das relações culturais e sociais dos sujeitos. Em uma rede de interações que se afetam mutuamente, todas as ações realizadas por um sujeito afetam outras dimensões de sua vida, gerando experiências e informações que dão origem ao saber simbólico do sujeito, ou informalmente à sua bagagem cultural, que são as tradições de conhecimento.

A partir da bagagem cultural e da cadeia de valores hierárquicos, a tradição se sustenta, em meio às memórias produzidas coletivamente ${ }^{9}$, da troca entre sujeitos, das demandas e ideias que surgem. Seu caráter legitimador facilita o processo de reconstrução sociocultural na modernidade (GRUNEWALD, 2003).

A tradição nessa concepção de transmissão e de elementos memorizantes, se fixa com uma criação humana, uma maneira de suprir uma necessidade, passível de ser retransmitida e reinterpretada, de modo que, não tem como se manter estagnada, uma vez que a cultura é continua. Com isso, novos valores vão ser criados em oposição aos valores tradicionais existentes, que irão perder seu espaço, se já não cumprirem mais o papel para o qual foram criados. Assim, os saberes tradicionais, permanecem em meio ao ciclo de criação/transformação social, porque, se moldam às alterações impostas pelo contexto em que estão inseridos (LENCLUD, 2013).

Como a tradição é socialmente constituída, Hobsbawm (1984) ressalta que ela não pode ser percebida como algo intocável, homogêneo e petrificado em um contexto atemporal. Reconhecendo-se as modificações culturais que ocorrem em todos os espaços/tempo, encontrar uma tradição dita em sua origem é uma tarefa impossível, pois, não existem meios ou registros para se saber quando começaram. Então, toda tradição é uma invenção, se manifesta por meio de ritos e costumes ligados a certos elementos do passado. Contudo, só é criada quando práticas antigas se dissolvem e se transformam. Nesse caso, os sujeitos possuem a necessidade de inventarem uma nova tradição, já que

\footnotetext{
${ }^{9}$ Memória Coletiva é uma representação, uma expressão da metamemoria, um discurso reproduzido sobre uma suposta memória comum e compartilhada como todos os sujeitos que compõem um grupo social (CANDAU, 2008).
} 
suas bases tradicionais anteriores desapareceram ou não são mais passiveis de serem seguidas. Por exemplo, a suposta tradição gaúcha (mitos de origem).

Em uma abordagem mais precisa:

[...] por "tradição inventada" entende-se um conjunto de práticas, normalmente reguladas por regras tácitas ou abertamente aceitas; tais práticas, de natureza natural ou simbólica, visam inculcar certos valores e normas de comportamento através da repetição, o que implica, automaticamente, uma continuidade em relação ao passado. Aliás, sempre que possível, tenta-se estabelecer continuidade com um passado histórico apropriado (HOBSBAWM,1984, p. 9).

$\mathrm{O}$ fim de uma tradição pode ser um processo doloroso, principalmente quando o idealizador/impositor de uma nova tradição é o Estado, o que era então estabelecido e conhecido é suplantado pelo novo e desconhecido. Os sujeitos têm que se adaptarem às novas regras de vida e de convivência em sociedade, suas identidades passam por um turbulento processo de influências modificadoras. Já o costume pressupõe-se na concepção de que é passível de mudança, desde que conserve certa compatibilidade com o costume do qual se originou (HOBSBAWM,1984).

A tradição para Candau (2011), é um mecanismo de transmissão, que possibilita que elementos fortemente organizados em estruturas socioculturais sólidas possam ser memorizados e assim compartilhados por muito tempo, no qual, a dualidade do lembrar e do esquecer permite as ações das tradições e sua existência.

Tal fenômeno maleável da cultura e da tradição pode ser observado no processo de guasqueria, que carrega em si elementos tradicionais, porém, com elementos de adaptação às modificações contextuais se apresentam. Segundo Luvizotto, a tradição nesse sentido:

[...] persiste e é (re) modelada e (re) inventada a cada geração. Assim, pode - se dizer que não há um corte profundo, ruptura ou descontinuidade absoluta entre o passado, o presente e o futuro. A compreensão do mundo é organizada pela tradição, pelo fato de ela ser fundamentada na superstição, na religião e nos costumes. A ordem social baseada na tradição expressa a valorização da cultura oral, do passado e dos símbolos enquanto fatores que perpetuam a experiência das gerações, e, nesse sentido, conhecer é ter habilidade para produzir algo e está ligado à técnica e à reprodução das condições do viver (LUVIZOTTO, 2010; p.66).

Dessa forma, a guasqueria possui esse caráter tradicional, devido a ser um ofício de técnicas aprendidas e transmitidas, em uma reprodução do saber-fazer do cotidiano, no caso o trabalho de peão. Para isso vale utilizarmos a declaração do guasqueiro Marcos Tissot (2016) que, com o seu pai que era um peão de estância, iniciou seu processo de aprendizagem em criar cordas de couro (Figura 02) que iriam ser utilizadas no serviço de 
campo. Já em sua maior idade, também seguiu na profissão de peão, principalmente por residir no espaço rural desde a sua infância. Como já sabia criar cordas de couro seu equipamento de montaria era todo produzido unicamente por ele. Com o passar dos anos ele diferencia o trabalho de peão do de guasqueiro, em suas palavras "depois mais adiante, que tu viras guasqueiro e só trabalhas nisso, é diferente de trabalhar como peão". Ele fez essa observação, devido ao fato de que na guasqueria possui liberdade para trabalhar. No serviço de peão, segue-se um horário de tempo especifico e tem que estar pronto para cumprir as mais diversas atividades campeiras.

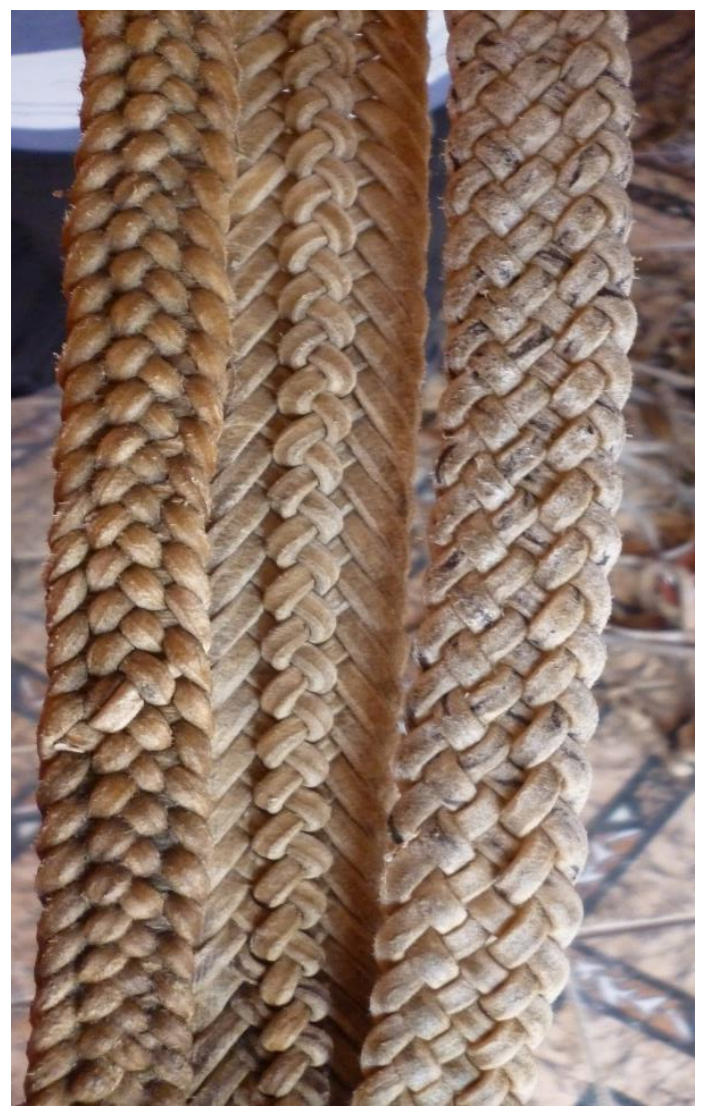

Figura 2-Cordas trançadas em couro cru

Fonte: Autora (2017)

As técnicas que seu pai lhe havia transmitido, de acordo com seu olhar, eram manejos simples, ou seja, apenas arremates de peças já prontas, mas que estavam danificadas. Fixando se no fato da base da guasqueria em transformar a matéria prima em um material maleável para se produzir, segue a sequência de estaquear, lonquear, sovar, cortar as guascas e tirar os tentos. É esta sequência de técnicas que o guasqueiro Marcos Tissot afirma que não muda. Em sua família ocorreu a transmissão de um saber-fazer de pai para filho, porém, 
ressaltou que o mesmo não ocorreu com o seu filho que nunca se interessou pelo ofício, acredita que isso aconteceu, porque "talvez se morasse no campo buscasse aprender como eu também”. Nessa perspectiva, percebemos a influência que o espaço rural e o trabalho como peão têm na vida do guasqueiro. Afinal, Marcos Tissot reside agora na cidade, zona urbana, não se dedica mais a lida campeira, mas segue sendo guasqueiro.

Nessa questão de transmissão do saber e do fazer, o guasqueiro Justus Soares (2016) também conta que aprendeu as técnicas de guasqueria com seu pai, que em sua percepção sabia apenas técnicas básicas de guasquear. Ensinou-lhe que para aprender guasqueria sempre se devia ficar observando atrás de quem está produzindo, acompanhando o movimento das mãos e os intricados caminhos dos tentos. A partir disso, aos dez anos já conhecia a base para ser um guasqueiro e com o passar dos anos foi se aperfeiçoando. Em sua infância também morou no campo, e já trabalhou de peão. Seu filho se interessou pelo ofício e aprendeu com ele os manejos da guasca.

Em relação aos dois primeiros casos, o guasqueiro Pedro Pires (2017) se diferencia, pois buscou aprender guasqueria por conta própria e foi atrás de informações sobre técnicas de criação em couro cru, mas, assim como os outros dois guasqueiros, também exerceu a profissão de peão e morou em sua infância no meio rural. Enquanto ainda era peão descobriu a necessidade de saber fazer cordas de couro, então começou a praticar os cortes de tentos (Figura 03), inicialmente esses saiam demasiadamente espessos. Certo dia ao observar um guasqueiro antigo a ensinar outra pessoa como se tira tentos finos para tranças aprendeu como fazer. E assim iniciou-se neste ofício por ser algo que "lhe agrada". 


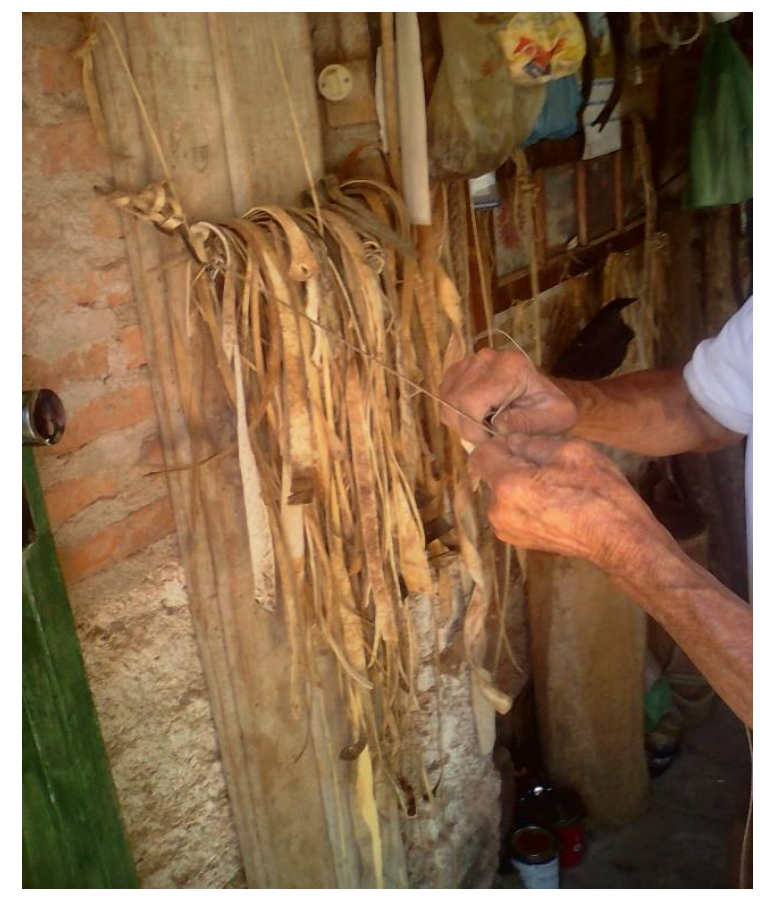

Figura 3-Tirando tento

Fonte: Autora (2017)

A técnica aprendida através da observação e de alguns ensinamentos com outros guasqueiros, lhe permitiu desenvolver sua própria forma de trabalhar o couro cru. Acredita que sua técnica de desenvolvimento com a prática tornou-se melhor, mais adequada, inicialmente errava muitas passadas de tentos para originar as tranças, porém conseguiu dominar essa habilidade ao repetir a ação muitas vezes. Ressalta a importância de cuidar do jeito em que se sova (Figura 04) a matéria-prima de acordo com ele é uma fase extremamente delicada, caso o guasqueiro não tenha cuidado pode danificar a guasca de couro ao sová-la de maneira errônea. 


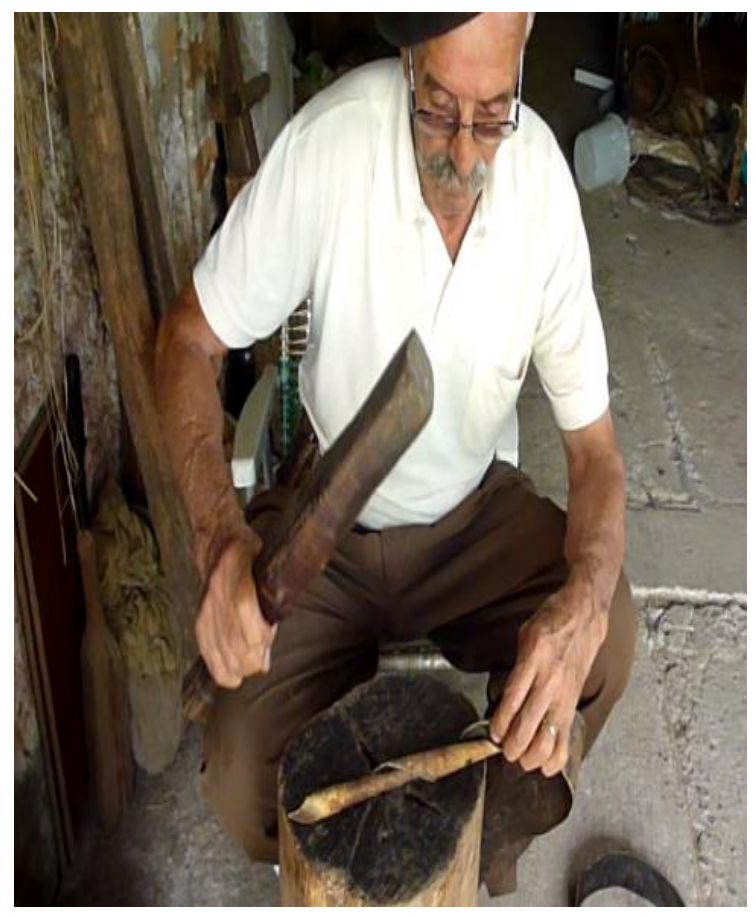

Figura 04-Guasqueiro Pedro Pires Sovando

Fonte: Autora (2017)

Em uma visão geral, podemos observar que os sujeitos que se dedicam a esta forma de expressão artesanal possuem uma forte ligação com a vida e o trabalho no campo. Iniciam nessa prática muito jovens, por estarem no contexto em que a guasqueria era algo necessário para o trabalho cotidiano do peão, ao criarem suas cordas e acessórios de montaria, e, principalmente, por um familiar, no caso a figura paterna, ou de algum conhecido, saber e transmitir seus conhecimentos sobre as técnicas artesanais em couro cru. Destaca-se também a similitude dos casos analisados ao nos depararmos com o fato de todos os guasqueiros terem sido também peões ou em um termo mais utilizado por eles, “campeiros". Demonstrando então que os objetos criados na guasqueria que segue uma linha tradicional, são os aparatos equestres como as boleadeiras, os freios, as rédeas, as maneias, os rebenques e outros.

Porém, eles não produzem apenas essas peças, algo que podemos notar como um fator de que a guasqueria não é algo estagnado; ao contrário, esses sujeitos aprenderam a bordar com tentos finos, e assim são capazes de fazer os mais intricados desenhos, trançarem para criarem botões para casacos, ou para fazer alguma peça de joalheria 
(ALVARES, 2014) ou de uso cotidiano, como cintas e chaveiros, além da adoção de nova matéria-prima, como o couro branco e a corda de seda ou náilon. Ressalta-se que o ateliê de produção das peças em guasca, na maioria dos casos, é o espaço onde esses sujeitos passam a maior parte de seus dias: o local remete muito a uma espécie de galpão com todos os aparatos, as ferramentas e peças de couro que compõem o cenário. Assim, o guasqueiro vive a guasqueria, é uma expressão de saber-fazer que pode ser considerada tradicional, e como toda tradição passa por transformações e readaptações.

\section{Guasqueiro ou artesão: A identidade e os guascas}

Como mencionado anteriormente a guasqueria possui elementos artesanais ligados a um aprendizado tradicional de transmissão de pai para filho, ou de guasqueiro para guasqueiro. A partir dessas considerações podemos iniciar uma discussão em torno da formação da identidade do guasqueiro, em seu autorreconhecimento de produtor desse ofício, em uma distinção pessoal entre artesanato e guasqueria. Para isso iremos utilizar alguns conceitos sobre identidade.

Partimos do pensamento de Candau (2011) ao afirmar que identidade é algo social, que se desenvolve nas interações entre sujeitos, das trocas de informações e das relações próximas (famílias, amigos, colegas de trabalho, conhecidos e outros), assim como dos contextos ao qual está inserido. Esse conjunto de fatores, influenciará na identidade do sujeito.

Nessa ação de influências o sujeito começa a construir sua identidade, em um discurso da diferenciação, em que Hall (2000) esclarece como sendo o momento em que eu me reconheço perante o outro, em um jogo de percepção de mim (quem sou, o que sou, o que quero, o que gosto, como sou), na criação da personalidade própria, em relação aos diversos grupos sociais de outros, aos que irei pertencer ou com os quais terei contato.

As diferenças de Eu e Outro demarcam o reconhecimento da diversidade identitária, do multiculturalismo, sendo para o autor a desvinculação de uma concepção de identidade homogênea. Em suas palavras: "mesmidade que tudo inclui, uma identidade sem costuras, inteiriça, sem diferenciação interna” (p. 109). Todos iguais, padronizados e em série, em que o diferente seria considerado errado e rechaçado.

A concepção ilusória de uma única identidade para todos, utiliza como ferramenta elementos de identificação compartilhados, objetos memorizantes de feitos gloriosos, que 
irão incutir um sentimento de pertencimento. Esse uso de mecanismos sociotransmissores ${ }^{10}$ (CANDAU, 2011) é um elo criado e transmitido de uma geração a outra, estabelecendo-se assim uma ideia de fazeres e ações usuais a todos, em uma estruturação social para a criação de uma identidade. Dessa forma, Hall, não está afirmando que a ideia de pertencimento a um grupo seja algo prejudicial, ele apenas esclarece que uma identidade única acaba sendo uma forma de exclusão daquelas pessoas que não se encaixam nas características consideradas adequadas à sociedade. Assim, podemos citar um exemplo utilizado pelo autor, para a criação de uma sociedade original, a estratégia de comunicação criada, que utiliza a ideia de uma identidade nacional, patriota, começa com a construção de uma ligação partilhada entre muitos.

Essa estratégia pode ser explicada através de cinco formas: a primeira utiliza a significação de nação, empregando os mecanismos de conhecimento bibliográfico como a história, ao relembrar, através de comemorações, as façanhas vitoriosas do passado. A segunda estratégia baseia-se na transmissão de uma tradição, de um passado que pode ser decifrado e rememorado a qualquer momento. Esse passado presente faz com que se produza uma identidade única que nunca se modifica, intrinsecamente aos sujeitos da mesma sociedade. Já a terceira, seria o caráter repetitivo da tradição, em seguir sempre os mesmos valores, ideais e práticas e códigos do passado, que regiam o comportamento moral da comunidade. Como penúltima estratégia o autor menciona a origem da construção de uma comunidade. A História novamente aparece como mecanismo de localização dos alicerces de fundação, dos grandes heróis e das lendas mitológicas que o tempo não pode apagar. Finalmente, a quinta estratégia se apresenta com a ideia de que todo o povo de uma nação é único, gerado em tal solo sem impurezas de outras sociedades (HALL, 2006).

Podemos perceber o papel da História na criação de uma nação hegemônica, como o meio de rememorar e recriar, onde o ciclo do tempo dividido em passado- presente-futuro seria inquebrável, sem descontinuidades nessas identidades homogêneas, rejeitando completamente a diversidade cultural. A diversidade passa a ser reconhecida na modernidade em meados do século XX, quando se iniciaram os movimentos identitários, em que as antigas identidades ditas autênticas, que estruturavam a sociedade, sofreram

\footnotetext{
${ }^{10}$ Esses elementos sócio transmissores para Candau (2011) incutem regras de comportamento e formas de organização humana na sociedade. Em uma diretriz de regulamentação da protomemória, na concretização de uma memória de alto nível e na continuidade da metamemória.
} 
rupturas. Com essas, a noção de unidade foi suplantada pela de diversidade. O sujeito moderno então possui identidades em um jogo de quebra-cabeça onde as peças já não formam um todo uno e estruturado. Em um discurso em que a identidade do Eu também é diferente de si em alguns momentos sociais. Como argumenta Hall (2006, p.21):

[...] a identidade muda de acordo como o sujeito é interpelado ou representado, a identificação não é automática, mas pode ser ganhada ou perdida. Ela tornou-se politizada. Esse processo é, às vezes, descrito como constituindo uma mudança de uma política de identidade (de classe) para uma política de diferença.

Nessa mudança do uno ao diverso, se faz importante mencionarmos três concepções de identidade encontradas em Hall, como a iluminista: o sujeito é o centro de tudo. O ser humano é dotado de todo o conhecimento e poder. Intrinsecamente permaneceria um Eu totalmente isolado. Conservar-se-ia idêntico/imutável e individual ao longo da existência, porém, sempre progressivo. A concepção sociológica: considera o sujeito sendo ativamente influenciado pelas relações sociais. O sujeito como um ser dependente de suas criações culturais, como signos, objetos e valores culturas. A identidade surgiria da troca entre o sujeito/eu e a sociedade/outro. E a concepção pós-moderna, que considera o estado de fragmentação do sujeito e do espaço social, sem a existência de um Eu permanente, de uma identidade universal e fixa.

Então, podemos utilizar como parâmetro do reconhecimento das diversidades identitárias, as mudanças socioculturais. O sujeito percebendo a pluralidade, as mesclas, os múltiplos, pois:

Nem a identidade de corte, caracterizada dos Estados burocráticos modernos, nem a identidade do empresário racional, impondo num mercado uma lógica racional econômica capitalista, nem o militante revolucionário, fundindo com a sua causa comunista e o aparelho que pretende encarná-la, podem servir de polo de identificação comum, universalmente legítimo e desejável (DUBAR, 2006; p.50).

A identidade como universal se divide em meio à infinidade de sociedades multiculturais. O discurso de identidade era "uma espécie de abrigo virtual ao qual é indispensável nos referirmos para explicar um determinado número de coisas, sem que este tenha jamais uma existência real" (STRAUSS, 1979, p.332).

No discurso de identidade, por conseguinte, retomamos a relação do Eu e o Outro (alteridade) que surge na formação de uma cultura, com a transformação do meio, da criação de signos, permitindo ao sujeito se reconhecer através da presença de outro agente. Como declara Passeron (1991, p.325): 
linguagem frequentemente prolixa da auto definição, sobretudo quando ela consegue se fazer teoria (mito, ideologia, religião, filosofia) para dizer e argumentar tudo o que os praticantes de uma cultura fazem-na significar, reivindicando-a como marca de sua identidade, por oposição a outras.

A oposição perante outros, faz com que surjam os conflitos identitários, que são de certa maneira demarcados, em uma luta de combate à diversidade, um sentimento de reconquistar o semelhante e a unidade. Neste processo, o outro de fora, estrangeiro e marginal, é assimilado e transformado em um dos nossos, em um empenho que deve partir dele mesmo em sua adaptação identitária. Pois, "sejam bem-vindos todos, de onde quer que tenham vindo, desde que todos, por mais longínquo seja o lugar de onde vieram, façam o mais rápido possível um esforço para tornar-se como nós” (LANDOWSKI, 2002; p.05).

Para tanto, a presença do outro à noção do coletivo, dos grupos ao qual se pertence influência diretamente na formação identitária, principalmente considerando o contexto social e cultural. Em vista disso Cuche (1999) coloca:

Não se pode pura e simplesmente confundir as noções de cultura e de identidade cultural ainda que as duas tenham uma grande ligação. Em última instância, a cultura pode existir sem consciência de identidade, ao passo que as estratégias de identidade podem manipular e até modificar uma cultura que não terá então quase nada em comum com o que ela era anteriormente. A cultura depende em grande parte de processos inconscientes. A identidade remete a uma norma de vinculação, necessariamente consciente, baseada em oposições simbólicas (p. 176).

Já em outra perspectiva, o autor define que a "identidade social de um indivíduo se caracteriza pelo conjunto de suas vinculações em um sistema social: vinculação a uma classe sexual, a uma classe de idade, a uma classe social, a uma nação" (p. 178).

Cuche alerta para os cuidados que se deve ter com a utilização de identidade social como mecanismo de inclusão, já que ela também pode ser identificada como um dispositivo de exclusão. Na mesma medida que inclui, essa concepção aparta, ou seja, "ela identifica o grupo (são membros do grupo os que são idênticos sob certo ponto de vista) e o distingue dos outros grupos (cujos membros são diferentes dos primeiros sob o mesmo ponto de vista)" (p.177). Com isso, temos na identidade tida como cultural um modelo de diferenciação das representações culturais, calcada nas diferenças culturais do Nós e Eles.

$\mathrm{O}$ autor trabalha com dois vieses, que definem a identidade, como o objetivista, em que a mesma se manifesta como algo próprio e vinculado ao sujeito, a ideia balizadora está nas raízes culturais do sujeito, estabelecendo a identidade como inalterável "a identidade seria preexistente ao indivíduo que não teria alternativa senão aderir a ela, sob o risco de se tornar um marginal, um "desenraizado". Vista desta maneira, a identidade é uma essência 
impossibilitada de evoluir" (p. 178).

Já na vertente subjetivista, a identidade torna-se elemento de identificação do sujeito frente ao grupo, sendo capaz de optar por determinadas coisas de maneira individual, ou seja, a identidade "como representações que os indivíduos fazem da realidade social e de suas divisões" (p. 181). Nessa visão, a identidade pode expressar sua diversidade.

A identidade parte das escolhas que fazemos, desde religião, a cor favorita, parte do se reconhecer através de um processo de alteridade frente a si mesmo e ao outro, em um jogo de olhares entre Eu e o Outro em que "as máscaras que exibimos então e depois ao mundo e aos seus habitantes são moldadas de acordo com o que se consegue antecipar desses julgamentos" (STRAUSS, 1999; p. 29).

De certa forma, o sujeito social ainda não compreende todas as nuances do sistema de reconhecimento de si e do outro, e as formas de se comunicar frente a isso. Nossa relação de comunicação com outro é instável e insegura, marcada pela tentativa insatisfatória de compreensão desse, porque buscamos nos posicionar sempre a partir do olhar do outro para demonstrarmos nossas identidades (DUBAR, 2005).

A sociedade está em um processo contínuo de hibridação, em que diversos fatores culturais tradicional/moderno e o homogêneo/diverso interagem entre si e dão origem a novas identidades. Já que "a identidade, mesmo em amplos setores populares, é poliglota, multitécnica, migrante, feita com elementos mesclados de várias culturas" (CANCLINI, 2008, p. 131).

Em relação à construção da identidade do Eu, Dubar (2005) afirma que ela é criada na infância e se modifica, se reestrutura e adapta-se durante o tempo de existência do indivíduo, ou seja, não é algo fixo e determinado. O sujeito só a produz em meio ao universo social, na dicotomia eu/nós, como já mencionado. Nesse sentido, a autora define identidade como:

A identidade nada mais é que, o resultado a um só tempo estável e provisório, individual e coletivo, subjetivo e objetivo, biográfico e estrutural, dos diversos processos de socialização que, conjuntamente, constroem os indivíduos e definem as instituições (DUBAR, 2005; p. 136).

Como já trabalhados pelos autores anteriores utilizados nesta pesquisa, Dubar reforça a concepção de identidade como uma criação social, influenciada pelo reconhecimento do outro e as mudanças culturais de seu contexto. Sendo então um fator móvel e contínuo.

Assim, a identidade percebida como diversa nos permite discutir a relação entre 
guasqueiro e artesão. No início dessa pesquisa ocorreu o questionamento: a guasqueria é uma prática artesanal, e, portanto, quem a pratica, seria artesão ou seria guasqueiro? Ou as duas denominações?

A forma mais eficiente para compreendermos esse questionamento parte dos próprios sujeitos que produzem guasqueria. Para tanto, ao perguntar diretamente ao guasqueiro Marcos Tissot (2016), esse observou surpreso e rapidamente disse "sou artesão". Esse comentário apressado foi justificado pelo simples fato de possuir uma carteira de artesão, disponibilizada pela prefeitura da cidade. Pois, em dado momento ele esclareceu "antes eu era guasqueiro". Mas então, ele pessoalmente reconhecia-se como guasqueiro, porém "eles não dizem guasqueiro quando se vai fazer a carteira, aí não sei dizer: pode ser guasqueiro, pode ser, acho que guasqueiro e artesão, os dois".

Então fica claro em sua fala a dúvida de como se identificar, sendo que ele ponderou sobre como se referia antes de possuir um documento que o classifica em seu ofício. Não obstante, também define como guasqueiro "trabalhar o couro cru, estaquear e lonquear para fazer as cordas" (MARCOS TISSOT, 2016), algo que destaca que ainda realiza.

Dessa forma, por possuirmos identidades, o guasqueiro Marcos Tissot pode se reconhecer como artesão por causa da carteira, e também pode ser guasqueiro, devido à forma que trabalha o couro cru. Como ressaltou Dubar (2005), a identidade de um sujeito está sempre em um processo de reinterpretação. A sociedade está relacionada com a identidade do artesão e de sua obra, e interfere nas relações de produção, execução e circulação do artesanato.

Nesse processo de interpretações de identidades, o guasqueiro Justus Soares (2016) acredita que a ideia de artesão é uma criação moderna, algo com o que ele não se identifica, pois, categoricamente afirma "sou guasqueiro, é minha profissão". Não importa se está aposentado, esse ofício faz parte de sua vida. Para ele, por ser atual a concepção de artesão, essa só se iguala à do guasqueiro porque também faz objetos manualmente. Nesse caso, a alteridade entre guasqueiro e artesão, faz com esse sujeito se autolegitime como guasqueiro.

Já ao questionar o guasqueiro Pedro Pires (2017), este elucidou peremptoriamente que é guasqueiro, devido a trabalhar com matéria prima natural, o couro cru em seu estado não tratado (com pelos). Menciona que é diferente do sujeito que produz com couro branco industrializado, uma matéria-prima que considera ruim. Além dessa distinção entre a matéria-prima, simplesmente não "lhe agrada", o termo artesão. Nesse caso, o sujeito está 
bem consciente do porquê se considera guasqueiro, ao trabalhar apenas com couro-cru. Esse fato é importante para entendermos que na guasqueria, para seus produtores, a matéria-prima é fator de determinação. Como também, a técnica de produção.

A forma e os objetos produzidos são elementos importantes para o guasqueiro Justus Soares (2016) na indagação sobre ser guasqueiro e/ou artesão "porque vejo os que se consideram artesões e fazem uns trabalhos tão assim, então por que não posso ser também, se eu faço esse trabalho tão rico?" (JUSTUS SOARES, 2016), referindo-se ao material exposto em seu ateliê.

Em suas observações, pode-se notar que não ocorreu nenhuma distinção entre ser artesão ou ser guasqueiro. Há o autorreconhecimento de ser um guasqueiro que produz artesanato, algo irregular, com manchas, com marcas e singular. Nessa imperfeição o artesanal se difere do industrial. E o ser guasqueiro ou/e artesão está presente na guasqueria, que pode comportar as duas formas de categorização.

\section{Considerações Finais}

As informações obtidas através de entrevista semiestruturada nos permitem tecer algumas conjecturas. Primeiramente, a guasqueria tem sua origem ligada ao homem do campo, ao trabalho nas fazendas de gado principalmente pelo fator de desenvolvimento da produção e comercialização do couro bovino cru. Os indígenas já utilizavam e transformavam essa matéria prima para criar objetos de uso cotidiano; logo, os peões de fazenda ${ }^{11}$ começaram a produzir seu equipamento de montaria, já que o custo dessas peças é elevado.

Podemos perceber a ligação da guasqueria com um ofício específico, o peão de estância e também, o valor da tradição na transmissão de um saber-fazer, de pai para filho, em seguir as bases de uma técnica, que é aperfeiçoada com o tempo, no caráter de repetir alguns gestos e padrões (na estrutura já mencionada de carnear, estaquear, secar, lonquear, sovar, cortar as guascas, tirar tento e trançar). Nesta repetição temos a identidade do sujeito guasqueiro que está sempre em um processo de autorreconhecimento e reinterpretação. Então, a guasqueria é um ofício que possui intrinsecamente em si tradições e identidades.

Por fim, torna-se fulcral compreendermos que a guasqueria considerada como

\footnotetext{
${ }^{11}$ Importante rememoramos que os guasqueiros desta pesquisa mencionaram serem filhos de peões, ou terem sido desta profissão em algum período de sua vida, e por esse motivo aprenderam a técnica da guasqueria, para consertar ou produzir seu material de trabalho.
} 
tradicional está em um constante processo de transformação e adaptação que influencia na identidade de seus produtores. Principalmente pela existência de uma confrontação na identificação de artesão e/ou guasqueiro. Assim, como emprego de outras matérias primas como o couro industrializado que modifica completamente a estrutura dorsal da guasqueria tradicional, uma vez que esse tipo de material não precisa ser amaciado e nem trançado, esse uso de produtos industrializados por parte dos guasqueiros é considerado por alguns como uma ruptura, momento em que o guasqueiro se torna artesão. Logo, a tradição e a identidade são elementos culturais que seguem um continuo fluxo de reinterpretações e jamais se estagnam.

\section{Referências Bibliográficas}

ALMEIDA, R. A inteligência do folclore. 2.ed. Brasília: INL, 1974.

ALVARES, Fabiano da Costa. Valorização dos Aspectos Formais dos Artefatos Confeccionados por Guasqueiros do Pampa Gaúcho Aplicados a Joalheria. Santa Maria: UFSM, 2014.

BARTH, Fredrik "Por um maior naturalismo na conceptualização das sociedades". In: Fredrik Barth (organização de Tomke Lask), O guru, o iniciador e outras variações antropológicas. Rio de Janeiro: Contra Capa Livraria, 2000.

CANCLINI, Néstor Garcia. Culturas Híbridas: estratégias para entrar e sair da modernidade. Trad. Ana Regina Lessa e Heloísa P. Cintrão. São Paulo: Edusp, 2008

CANDAU, Joel. Memória e identidade. Tradução: Maria Leticia Ferreira. São Paulo: Contexto, 2011.

Mémore Colletive et mémoire individuelle foncionnent-elles selon le même modele? Archives, 2008.

DLE. Diccionario online de la Real Academia Española. Acesso em: 10 de maio de 2017 Disponível em: http://dle.rae.es/

DUBAR, Claude. A socialização: construção das identidades sociais e profissionais. São Paulo: Martins fontes, 2005.

A Crise das identidades. A interpretação de uma mutação. Porto: Edições afrontamento, 2006.

FLORES, Luis Alberto. El Guasquero: Trenzados Criollos. Buenos Aires: Cesarini Hermanos, 1960

GADAMER, Hans-Georg. Verdad y Método In:Fundamentos de una hermenéutica

filosófica. Salamanca: Ed. Sígueme,1996. (Trad. Ana Agud Aparicio e Rafael de Agapito).

GEERTZ, Clifford. A Interpretação das Culturas. Rio de Janeiro: LTC, 2008.

GOOGLE MAPS. Jaguarão-RS, 2018. Disponível em:

https://www.google.com.br/maps/place/Jaguar\%C3\%A3o+-+RS,+96300-000/@- 
30.2938778,53.7712252,7z/data $=! 4 \mathrm{~m} 5 ! 3 \mathrm{~m} 4$ !1s0x950e62b2af53f611:0xd28551cff28e69c5!8 m2!3d-32.3385963!4d-53.4770359 Acesso em: 27 de outubro de 2018.

GRUNEWALD, Rodrigo de Azeredo. Horizontes Antropológicos. Porto Alegre, ano 9, $\mathrm{n}^{\circ}$. 20, p. 141-159, outubro de 2003;

HALL, Stuart. A identidade cultural na pós-modernidade. Rio de Janeiro: DP\&A Editora, 2006.

HOBSBAWM, Eric \& RANGER, Terence. A Invenção das Tradições. Rio de Janeiro:Paz e Terra, 1984.

LANDOWSKI, Eric. Presenças do outro. São Paulo: Perspectiva, 2012.

LEAL, Ondina Fachel. Honra, morte e masculinidade na cultura gaúcha. In: TEIXEIRA, Sérgio Alves. ORO, Ari Pedro. (orgs). Brasil e França: Ensaios de Antropologia Social. PPGAS - UFRGS, n. 6. 1992.

LENCLUD, Gérard. A Tradição não é mais o que era: Sobre as noções de Tradição e de Sociedade Tradicional em Etnologia. Brasília: História, histórias. vol. 1, n. 1, 2013.

LUGON, Clovis. A Republica Cristã dos Guaranis: 1610-1668. Tradução de Álvaro Cabral , prefácio de Henri Charles Desroches. $3^{\text {a }}$ ed. Rio de Janeiro: Paz e Terra, 1977.

LUVIZOTTO, Caroline Kraus. As tradições gaúchas e sua racionalização na modernidade tardia. São Paulo: Editora UNESP; São Paulo: Cultura Acadêmica, 2010. PASSERON, Jean-Claude. 1991. Le Rai sonnement Sociologique. Lespace NonPopperien du Raisonnement Naturel. Paris: Nathan.

THOMPSON, E.P. Costumes em comum - Estudos sobre cultura popular tradicional. São Paulo: Companhia das letras, 1998.

Recebido em 10 de setembro de 2018.

Aceito em 20 de outubro de 2018. 